\title{
Epidemiological and sociocultural study of burn patients in Alexandria, Egypt
}

Ashraf F. Attia, ${ }^{\text {Aida A. Sherif, }}{ }^{2}$ Ahmed M. Mandil, ${ }^{2}$ M. Nabil Massoud, ${ }^{3}$ Mervat W. Abou-Nazel 4 and Moustafa A. Arafa ${ }^{2}$

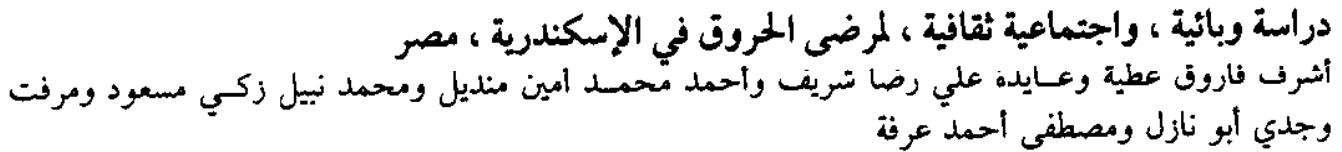

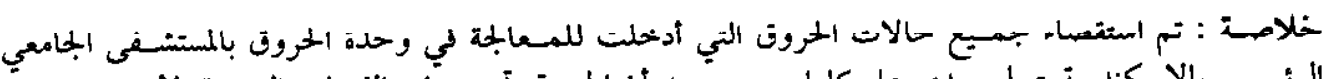

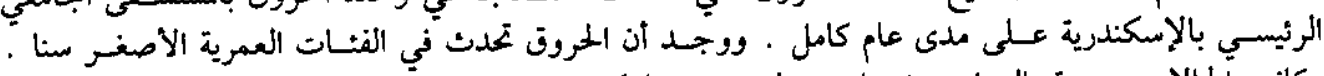

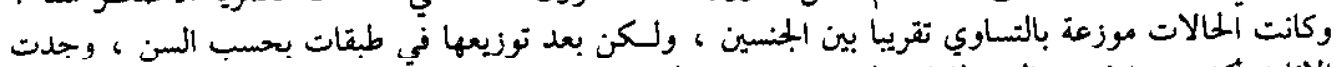

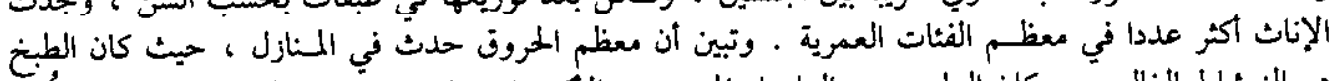

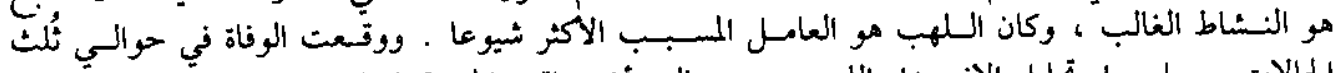

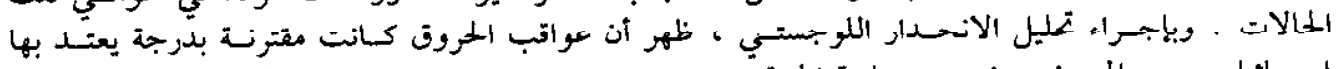

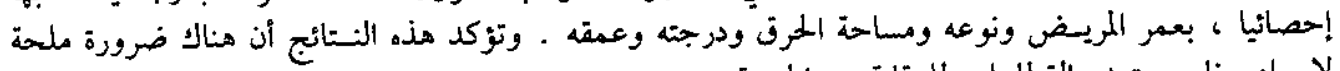

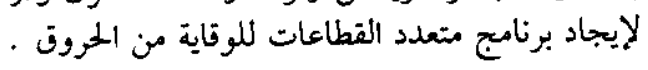

ABSTRACT All burn cases admitted to the burns unit of Alexandria Main University Hospital over a period of one year were investigated. Bums were found to occur in younger age groups. There was an almost equal distribution of cases by sex, but when stratified by age, more females were found in most age groups. Most bums were domestic, with cooking being the most prevalent activity. Flame was the most common agent. Death occurred in about one-third of cases; when using logistic regression analysis, the outcome of the burn injury was significantly associated with age, sex, total surface area burnt and degree and depth of the bum.

\section{Etude épidémiologique et socioculturelle des brôlós a Alexandrie (Egypte)}

Résumé. Tous les cas de brôlures admis au Service des brûlés de l'Hôpital universitaire d'Alexandrie sur une période d'un an ont été examinés. Il a été constaté que les brûlures se produisaient dans les groupes d'áge les plus jeunes. II y avait une répartition presque égale des cas en fonction du sexe, mais lorsqu'une stratification par ảge a été effectuée, on a trouvé davantage de femmes dans la plupart des groupes d'åge. La plupart des brúlures étaient d'origine domestique, la cuisine étant l'activité impliquée dans la majorité des cas. L'agent le plus souvent en cause était le feu. Le décès est survenu dans environ un tiers des cas; lorsqu'on utilise l'analyse de régression logistique, l'issue de la brûlure est associée de manière significative avec l'âge, le sexe, la surface totale des lésions ainsi que le degré de brûlure et la profondeur de la brûlure.

\footnotetext{
'Preventive Medicine Department, Egyptian Naval Forces, Alexandria, Egypt. 'Epidemiology Department, High institute of Public Maalth Alexandria. Eovpt. ${ }^{3}$ Faculty of Medicine; 'Mental Health Division, Alexandria University, Alexandria, Egypt. Received: 20/03/97; accepted: 11/09/97
} 


\section{Introduction}

Injuries represent one of the most important public health problems facing both developing and industrialized nations today. Injuries may be either intentional or nonintentional; but intent is sometimes difficult to determine for injuries such as burns.

Burns represent an extremely stressful experience for both the burn victims as well as their families. An extensive burn profoundly affects the patient's physique, psyche, financial situation and family. $\mathrm{Pa}-$ tients with extensive burns frequently die, and for those with lesser injury, physical recovery is slow and painful. In addition to their dramatic physical effects, burn injuries frequently cause deleterious psychological complications.

As the etiological factors of burn injuries vary considerably in different communities, careful analysis of the epidemiological features in every community is needed before a sound prevention programme can be planned and implemented. This study was conducted to identify demographic and sociocultural aspects of burn patients, to investigate the factors affecting outcome and mortality of burns and to determine the magnitude of the problem of burns among all injuries admitted to the Alexandria Main University Hospital over a period of one year.

\section{Subjects and methods}

All burn cases admitted to the burns unit of Alexandria Main University Hospital over a period of one year $(n=533)$ were subjected to a questionnaire-interview to obtain the following data:

- Registration data: age, sex, residence, level of education, occupation, marital status, crowding index (number of per- sons per number of habitable rooms) and income.

- Circumstances of the injury: place and time, brief description of the event, agent, associated burning of clothes, patient's and attendants' reaction, first-aid measures taken.

- Clinical assessment of the wound: site affected, total surface area burnt (TSAB), degree, depth, severity, complications.

- Chronological data: dates of admission and discharge.

The data were obtained by questionnaire-interview with the patient themselves, if they were mature and well enough to answer the questions. In the case of younger children or patients who were not well enough as a result of severe injury, the data were obtained from relatives who attended the unit. It should be noted that visits to patients admitted to the unit are forbidden but visitors can make a phone call to patients from the social workers" office within the unit. The visitors may inquire about the patients' condition through the social workers, the nursing staff and/or the unit's doctor.

The total number of burn cases throughout the study year were compared with the total number of all injuries admitted during the same period to determine the proportion of burn injuries among them. The total number of all injuries was obtained through revision of the data from the registries of the Emergency Unit, the Statistics Department and the Alexandria Poison Centre.

\section{Data analysis}

The data were entered into Epi-Info on computer and subsequently exported to SPSS. The relationship between mortality and selected indicators from data of the patients' profiles was studied using multivari- 
ate logistic regression analysis and hierarchical log-linear analysis.

Logistic regression analysis can explain a significant amount of the variation in the patient factors studied. The following variables were used to develop the model: age and sex, agent of the burn, delay in seeking medical care, TSAB, degree and depth of the burn wound, occurrence of complications, clothing ignition and intent of the injury. The percentage of cases correctly classified is used as a measure of the goodness of fit of the model.
Hierarchical log-linear analysis is a method of finding the best linear association of a set of categorical variables which can represent data, where the natural logs of cell frequencies rather than the actual count are used. The value of the standardized residual is considered to be significant when it ranges from -1.96 to +1.96 . The best model which described our data included the following variables: condition on discharge, age and sex of the burn patient and TSAB.

Table 1 Sociodemographic data

\begin{tabular}{|c|c|c|c|c|c|c|c|c|}
\hline \multirow[t]{3}{*}{ Variable } & \multicolumn{6}{|c|}{ Sex } & \multicolumn{2}{|c|}{ Sionificance } \\
\hline & \multicolumn{2}{|c|}{ Male } & \multicolumn{2}{|c|}{ Female } & \multicolumn{2}{|c|}{ Total } & \multirow[t]{2}{*}{$x^{2}$} & \\
\hline & No. & $\%$ & No. & $\%$ & No. & $\%$ & & \\
\hline Age group (years) & & & & & & & 12.8 & $>0.05$ \\
\hline-5 & 51 & 49.4 & 52 & 50.6 & 103 & 19.3 & & \\
\hline-10 & 19 & 67.9 & 9 & 32.1 & 28 & 5.3 & & \\
\hline-20 & 55 & 45.8 & 65 & 54.2 & 120 & 22.5 & & \\
\hline-30 & 61 & 44.5 & 76 & 55.5 & 137 & 25.7 & & \\
\hline-40 & 47 & 63.5 & 27 & 36.2 & 74 & 13.9 & & \\
\hline-50 & 17 & 48.6 & 18 & 51.4 & 35 & 6.6 & & \\
\hline-60 & 5 & 35.7 & 9 & 64.3 & 14 & 2.6 & & \\
\hline-90 & 11 & 50.0 & 11 & 50.0 & 22 & 4.1 & & \\
\hline Total & 266 & 49.9 & 267 & 50.1 & 533 & 100 & & \\
\hline Level of education & & & & & & & $24.2^{*}$ & 0.000 \\
\hline Illiterate & 48 & 37.5 & 80 & 62.5 & 128 & 31.0 & & \\
\hline Primary & 64 & 60.4 & 42 & 39.6 & 106 & 25.7 & & \\
\hline Preparatory & 30 & 39.5 & 46 & 60.5 & 76 & 18.4 & & \\
\hline Secondary & 52 & 59.1 & 36 & 40.9 & 88 & 21.3 & & \\
\hline University & 12 & 80.0 & 3 & 20.0 & 15 & 3.6 & & \\
\hline Total & 206 & & 207 & & 413 & & & \\
\hline Marital status ${ }^{b}$ & & & & & & & $26.8^{*}$ & 0.000 \\
\hline Married & 68 & 36.0 & 121 & 64.0 & 189 & 52.1 & & \\
\hline Single & 96 & 62.7 & 57 & 37.2 & 153 & 42.1 & & \\
\hline Widowed & 8 & 42.1 & 11 & 57.9 & 19 & 5.2 & & \\
\hline Divorced & 1 & 50.0 & 1 & 50.0 & 2 & 0.6 & & \\
\hline Total & 173 & & 190 & & 363 & & & \\
\hline
\end{tabular}

120 cases (22.5\%) were below the age of education ( $\geq 6$ years)

${ }^{\circ} 70$ cases (31.9\%) were below the legal age of marriage (male $>18$ years, female $>16$ years)

statisticaly significant 


\section{Results}

\section{Sociodemographic characteristics (Table 1)}

The ages of the burn patients ranged from 6 months to 81 years $(\bar{x}-22.95 \pm 16.7$ years); most of the cases (86.7\%) were $\leq$ 40 years of age. Differences in age distribution by sex were not statistically significant $(P>0.05)$.

Among patients of the age of education (6 years and above; $n=413$ ), about onethird were illiterate; those who were university graduates represented only $3.6 \%$. Females were found more often among the illiterate group, while more males were found among primary, secondary and uni- versity graduates. However, the association was not statistically significant $(P>0.05)$.

The majority of patients $(67.2 \%)$ were not working. Of those, $31 \%$ were below school age, $25 \%$ were students, $41 \%$ were housewives and $3.2 \%$ were retired. Of the working group, more than half of the patients were manual workers, followed by technical workers ( $29 \%$ ); clerical, commercial and professional workers represented a total of about $17 \%$. More females (64\%) were found in the married group and more males $(63 \%)$ in the single group. Differences in marital status by sex were statistically highly significant.

The crowding index ranged from 0.2 to $9.0(\bar{x}=2.4 \pm 1.1)$.

\begin{tabular}{|c|c|c|c|c|c|c|c|c|}
\hline \multirow[t]{3}{*}{ Variable } & \multicolumn{6}{|c|}{ Sex } & \multicolumn{2}{|c|}{ Significance } \\
\hline & \multicolumn{2}{|c|}{ Male } & \multicolumn{2}{|c|}{ Female } & \multicolumn{2}{|c|}{ Total } & & \multirow[t]{2}{*}{$\boldsymbol{P}$} \\
\hline & No. & $\%$ & No. & $\%$ & No. & $\%$ & & \\
\hline Place & & & & & & & $38.9^{\star}$ & $<0.001$ \\
\hline Domostic & 223 & 45.8 & 264 & 54.2 & 204 & 54.2 & & \\
\hline Occupational & 24 & 96.0 & 1 & 4.0 & 25 & 4.7 & & \\
\hline Street & 19 & 90.5 & 2 & 9.5 & 21 & 3.9 & & \\
\hline Agent & & & & & & & $26.65^{*}$ & $<0.001$ \\
\hline Flame & 157 & 44.1 & 199 & 55.9 & 356 & 66.8 & & \\
\hline Scald & 77 & 55.0 & 63 & 45.0 & 140 & 26.3 & & \\
\hline Electrical & 17 & 81.0 & 4 & 19.0 & 21 & 3.9 & & \\
\hline Chemical & 15 & 93.8 & 1 & 6.2 & 16 & 3.0 & & \\
\hline Clothing ${ }^{a}$ & & & & & & & $18.24^{*}$ & $<0.001$ \\
\hline Ignition & 115 & 39.0 & 180 & 61.0 & 295 & 82.9 & & \\
\hline No ignition & 42 & 68.9 & 19 & 31.1 & 61 & 17.1 & & \\
\hline Total & 157 & & 199 & & 356 & & & \\
\hline Intent & & & & & & & $16.6^{*}$ & $<0.001$ \\
\hline Unintentional & 242 & 50.9 & 233 & 49.1 & 475 & 89.1 & & \\
\hline Suicidal & 7 & 30.4 & 16 & 69.6 & 23 & 4.3 & & \\
\hline Homicidal & 12 & 85.7 & 2 & 14.3 & 14 & 2.6 & & \\
\hline Undetermined & 5 & 23.8 & 16 & 76.2 & 21 & 3.9 & & \\
\hline Total & 266 & & 267 & & 533 & & & \\
\hline
\end{tabular}

Ignition of clothing wae roported among only flamo-bumi patients (350 cases) - Statistically significant 


\section{Circumstances of the injury}

(Table 2)

The majority of burn injuries $(91.4 \%)$ occurred in the home. The place of occurrence of the injury and sex were found to be significantly associated; the vast majority (93\%) of occupational and street burns occurred among males. More than half of domestic cases $(56.9 \%)$ occurred in the kitchen; those which occurred in the bathroom represented $20.4 \%$. Cooking was the activity most often responsible for burn occurrence $(63.5 \%)$.

Regarding seasonal distribution, more cases were encountered during the summer and spring (29.6\% and $27.8 \%$ respectively). The association between season and occupation was not significant.

Flame represented the most common agent of burn injuries $(66.8 \%)$ and tended to affect more females than males; kerosene stoves were the most common source $(53.2 \%)$. The agent and the place of occurrence of the burn injury were significantly associated; most flame, scald and electrical burns $(94.9 \%, 95.0 \%$ and $61.9 \%$ respectively) were domestic, while most chemical burns (56.3\%) occurred in the street. Most of the burns in the age group $<10$ years were by scalding $(76.3 \%)$, while flame was the most common agent in other age groups. Clothing ignition was reported in $82.9 \%$ of flame burn patients and $61 \%$ of them were females. Among those with clothing ignition, $71 \%$ were wearing clothing made of synthetic material, $20 \%$ had clothes soiled with flammable liquids and $51 \%$ were wearing tight clothing.

\section{Clinical assessment of the burn wound (Table 3)}

Most cases were either mixed second and third degree burns or isolated second degree $(49.2 \%$ and $44.3 \%$ respectively). The burn agent was significantly associated with the degree, depth and severity of the burn wound; flame burns tended to cause mixed second and third degree, deep and severe burns. A significant association was found between the occurrence of clothing ignition and depth of the burn.

\section{Outcome and factors affecting mortality}

The length of hospital stay ranged from 0.2 to 138 days $(\bar{x}=16.2 \pm 19.5$ days $)$. For survivors, the mean length of stay was 21.5 days ( \pm 21.7 ), while that for those who died

Table 3 Clinical assessment of the burn wound

\begin{tabular}{|c|c|c|c|c|c|c|c|c|c|c|}
\hline \multirow[t]{3}{*}{ Variable } & \multicolumn{8}{|c|}{ Burn agent } & \multicolumn{2}{|c|}{ Significance } \\
\hline & \multicolumn{2}{|c|}{ Flame } & \multicolumn{2}{|c|}{ Scald } & \multicolumn{2}{|c|}{ Electrical } & \multicolumn{2}{|c|}{ Chemical } & & \\
\hline & No. & $\%$ & No. & $\%$ & No. & $\%$ & No. & $\%$ & & \\
\hline Degree & & & & & & & & & 84 & $<0.001$ \\
\hline First and second & 12 & 3.4 & 15 & 10.7 & $\begin{array}{r}0 \\
17\end{array}$ & 0.0 & $\begin{array}{r}1 \\
10\end{array}$ & $\begin{array}{l}6.25 \\
62.5\end{array}$ & & \\
\hline Second & 99 & 27.8 & & & 17 & 81.0 & 3 & 12.5 & & \\
\hline Third & 3 & 0.8 & 0 & 0.0 & 2 & 9.5 & & 18.8 & & \\
\hline Second and third & 242 & 68.0 & 15 & 10.7 & 2 & 9.5 & 3 & 18.8 & & \\
\hline Depth & & & & & & & & & a119 & $<0.001$ \\
\hline Superficial & 75 & 21.1 & 97 & 69.3 & 17 & 81.0 & 6 & 37.5 & & \\
\hline Deep & 281 & 78.9 & 43 & 30.7 & 4 & 19.0 & 10 & 62.5 & & \\
\hline Total & 356 & 66.8 & 140 & 26.3 & 21 & 3.9 & 16 & 3.0 & & \\
\hline
\end{tabular}


Table 4 Adjusted odds ratio for factors affecting condition on discharge

\begin{tabular}{lc}
\hline Risk factors & Adjusted OR (Cl) \\
\hline $\begin{array}{c}\text { Age (years) } \\
10-20\end{array}$ & $0.5(0.1-1.8)$ \\
-40 & $0.3(0.1-0.7)$ \\
-60 & $0.7(0.2-2.5)$ \\
-90 & $18.1(4.3-75.5)$ \\
Sex & $3.2(1.6-6.4)$ \\
TSAB (\%) & \\
$20-40$ & $6.4(2.3-17.7)$ \\
$40-100$ & $59.6(13.0-273.4)$ \\
Degree & \\
Third & $1.2(0.04-33.6)$ \\
First and second & $0.2(0.01-3.6)$ \\
Second and third & $5.3(1.9-15.3)$ \\
Depth & $22.3(7.2-09.5)$ \\
\hline
\end{tabular}

$O R=$ odds ratio $\quad \mathrm{Cl}=$ confidence interval

$T S A B=$ total surface area bumt

was 5.3 days $( \pm 5.1$ ). The case fatality rate was $33 \%$. Mortality was significantly associated with age and sex of the burn victim, TSAB, agent, occurrence of clothing ignition, degree, depth and severity of the burn wound, delay in seeking medical care and occurrence of inhalation burns.

When logistic regression analysis was applied, it was found that age, sex, TSAB and degree and depth of burn were significantly associated with mortality (Table 4). The percentage of cases correctly classified was found to be $94.7 \%$.

Using hierarchical log-linear analysis, it appears from the model that the case fatality rate significantly increased with increased TSAB and at the extremes of age (Table 5). As regards sex, it was found that in all TSAB groups and among all age groups, the male:female ratio ranged from $1: 1.1$ to $1: 5.0$, except for those who had $0 \%-20 \%$ TSAB where the male:female ratio in the age group $0-10$ years was 1.5:1.
Table 5 Distribution of deaths according to TSAB, age and sex for use hierarchical loglinear analysis

\begin{tabular}{lrrr}
\hline Age (years) & & Sex & Total \\
& M & F & \\
\hline TSAB 0\%-20\% & & & \\
$0-10$ & 3 & 2 & \\
$11-20$ & - & 1 & \\
$21-40$ & 1 & 2 & \\
$>40$ & 3 & 4 & \\
Total & 7 & 9 & 16 \\
TSAB 20\%-40\% & & & \\
$0-10$ & 4 & 7 & \\
$11-20$ & 4 & 7 & \\
$21-40$ & 6 & 15 & \\
$>40$ & 3 & 14 & \\
Total & 17 & 43 & 60 \\
TSAB 40\%-100\% & & & \\
$0-10$ & 2 & 5 & \\
$11-20$ & 7 & 27 & \\
$21-40$ & 7 & 35 & \\
$>40$ & 8 & 9 & \\
Total & 24 & 76 & 100 \\
\hline TSAB & & &
\end{tabular}

$T S A B=$ total surface area bumt

$M=$ male $\quad F=$ fomalo

Standardizod rosidual $=+1.90$ to -1.90

\section{Discussion}

Injuries and their related morbidity, disability and mortality represent a public health problem of increasing importance in developing countries. Economic development coupled with a remarkable decrease in the infectious disease rate have increased the importance of injuries as a leading cause of premature death and disability in such countries [1,2]. Epidemiological studies of morbidity are a prerequisite for effective burn prevention programmes, both because each population seems to have its own epidemiological characteristics and because knowledge of the epidemiology of burns is 
needed to select target groups for preventive actions.

Age and sex are important epidemiological determinants for injuries, including burns. The present study revealed that about one-fifth of the studied sample was $<5$ years of age; nearly half of the cases were aged 10-40 years, while those aged 50 years and over represented $6.7 \%$ of the cases. The age distribution revealed by the present study is similar to that found in othcr studics $[3,4]$. However, the discrepancy between the relatively low percentage of old people in the present study and the higher percentage $(16.7 \%)$ reported by Glasheen et al. in the United States of America (USA) [5] might be explained by the social structure in Egypt, where older members usually live within the family and are served by younger family members, thus decreasing their exposure to hazardous situations and hence their liability to injury.

This pattern means that burns tend to occur more in certain age groups reflecting the particular developmental or behavioural patterns associated with age. In children, the lack of coordination and unawareness of dangerous substances play important roles in the occurrence of burns. In addition, young children are not adequately supervised because of large families and the lack of domestic safety measures. High incidence among young adults, on the other hand, may be explained by the fact that they are generally active and exposed to hazardous situations both at home and at work.

As regards sex distribution, the female preponderance in the age group 20-40 years concurs with other reports from developing countries such as India [6] and Jordan [7], as well as other Egyptian studies [8,9], and might be explained by the involvement of females of this age group in domestic activities. On the other hand, the male predominance in the younger age group (5-10 years) might be explained by the inquisitive and exploring nature of boys of this age. This finding concurs with other reports from different countries $[6,10,11]$, as well as from Egypt $[9,12]$. In industrialized countries, the sex distribution of burn cases differs, where males generally have a significantly higher risk $[5,13]$. This might be explained by the higher incidence of industrial and recreational burns among males in such countries.

With regard to seasonal distribution of cases, summer had the highest percentage $(29.6 \%)$, followed by spring $(27.8 \%)$ but the seasonal difference was statistically insignificant. This finding is in agreement with an earlier study performed in Alexandria [9].

With respect to the place where the burn injury occurred, the majority of burns $(91.4 \%)$ occurred in the home. This figure is comparable to other reports from developing countries, including Egypt. In Egypt, the reported figures $[1,9,14]$ range from $75 \%$ to $84 \%$. Other reports from South Africa [15], India [16], Njgeria [17] and Ghana [18] have figures ranging from $71 \%$ to $92 \%$. Reports from industrialized countries indicate that domestic burns are also the commonest, as reported in the USA (46.1\%)[19]. However, figures from industrialized countries are clearly lower than those reported from developing countries. This may be due to the relatively higher percentage of occupational and recreational burns or to better home safety with safer cooking and heating devices in industrialized countries.

In the present study, most burns were unintentional (89.1\%); suicidal and homicidal injuries represented $4.3 \%$ and $2.6 \%$ respectively. These figures are comparable to an earlier study in Alexandria [9], where unintentional burns represented $85.3 \%$ of the cases. The percentage of confirmed sui- 
cides in the present study is similar to that reported in India (4\%) [20], but lower than that reported in Jordan $(13.5 \%)[21]$. It was found that most of the cases of undetermined intent followed the pattern of suicidal intent as regards time of occurrence, agent of the burn and TSAB. Thus, if the figures for suicidal injuries (4.3\%) and undetermined intent $(3.9 \%)$ were added together, this would come to about $8.3 \%$, which is closer to the figure reported by Kamcl in Egypt [9].

Considering the agent of the burn injury, flame was the most common agent, affecting about two-thirds of cases, followed by scalds $(26.3 \%)$. Similar results have been reported from Egypt [9,14], India [20] and Jordan [21]. As regards the source of flame, portable pressure kerosene stoves were the most common source and were responsible for slightly more than hialf (53.2\%) of the cases. This is consistent with the findings of previous studies in developing countries $[15,10]$, as well as in Egypt $[8,9]$. On the other hand, the picture reported from industrialized countries differs, where flammable liquids and gas stoves were the most common source of flame burns $[19,22]$. Burn agents are highly individualized in each country, largely depending on the standard of living and lifestyle.

In spite of the finding that scalds were responsible for only $26.3 \%$ of burn injuries in this sample, they were found to be the most frequent agent of burn injuries in reports from Japan [23] and Nigeria [24], in which they represented $40 \%-78 \%$. The difference in ranking of different agents could be attributed to the developmental stage of the country, the age composition of the sample and whether outpatients were included or not.

In the present study, a significant association was found between age and agent of burn injury. Most scald burns (76.5\%) oc- curred in children $\leq 10$ years, while in the older age groups flame was the most common agent. These results are in agreement with those reported from Australia [25], Jordan $[21]$ and Egypt $[8,9,12]$. Associated clothing ignition was identified in $83 \%$ of flame cases. Clothing ignition has been identified as a major cause of burns in both industrialized and developing countries. However, in industrialized countries, a change to more closely fitting styles of clothing, together with decreased fabric flammability, has resulted in a significant decrease in deaths from clothing ignition, which represented only $5 \%$ of all burn deaths in the USA [26].

Mortality is the most important and most readily quantifiable outcome in burn patients. In the present study, the case fatality rate was $33 \%$. When univariate analysis was used, a higher case fatality rate was observed with older age groups, with flame agent, especially if clothing was ignited, with larger TSAB, with deep burns and with higher degree, especially if the patients delayed seeking hospital admission. These results are consistent with other reports $[27,28]$.

When applying logistic regression analysis to a model of 10 variables which were significantly associated with mortality, five factors were found to be significantly different between the survivors and those who died. These variables were age, sex, TSAB, degree and depth of burn. The accuracy of the model used was $94.7 \%$ which is comparable to other models [27-29]. Multivariate regression analysis for burns mortality predictlon in other studies has Identifled similar independent variables. TSAB was found significant in some models [29-31], while age was significant in other models [3032]. Sex was significant in one model [34]. The depth and degree were significant in these models but they were used in conju- 
gation with TSAB, presenting it as percentage full thickness burn and percentage partial thickness burn. The variability of these results may indicate differences in treatment protocols, which influence ultimate mortality [27].

With regard to the contribution of burn injuries to all injuries admitted to Alexandria Main University Hospital during the study period, burns were responsible for $5.6 \%$ of all admitted injuries. This figure is comparable to others from Egypt, as well as other countries, which range from $4 \%$ to $20 \%$ [33-36]. However, the actual condition may be worse as the figure does not include cases which may have died before they reached hospital. In addition, the relatively low percentage of cases compared with other reports may be due to the non-inclusion of mild cases, which were treated on an outpatient basis. Although burn patients may appear numerically few, they comprise a patient group often requiring considerable resources because of the need for repeated grafting procedures, hygienic precautions, treatment of infections and supportive care to patients and their families.

\section{Rererences}

1. Mashaly AM, Graitcer PL, Youssef ZM. Injury in Egypt: injury as a public health problem. Cairo, 1993.

2. McLoughlin E, McGuire A. The causes, cost and prevention of childhood burns injuries. American journal of diseases of children, 1990, 144:677-83.

3. Subrahmanyam M. Topical application of honey in treatment of burns. British journal of surgery, 1991, 78:497-8.

4. Ytterstad B, Sogaard AJ. The Harstad Injury Prevention Study: prevention of burns in small children by a communitybased intervention. Burns, 1995, 21(4):259-66.

5. Glasheen WP et al. Identification of the high risk population for serious burn injuries. Bums, 1983, 9(3):193-200.

6. Sen R, Banerjec C. Survey of 1000 admissions to a bums unit, SSKM Hospital, Calcutta. Burns, 1981, 7(5):357-60.

7. Abu Ragheb S, Qaryoute S, el-Muhtaseb $\mathrm{H}$. Mortality of burn injuries in Jordan. Burns. 1984. 10(6):439-43.
8. Massoud MN, Mandil AMA. Towards a burns prevention programme for children and adolescents in Alexandria. Alexandria journal of pediatrics, 1992, $6(3): 641-5$.

9. Kamel FA. Some epidemiological features of burn patients admitted to the emergency department of the Main University Hospital and to Ras El-Teen Hospital in Alexandria [MPH thesis]. Alexandria, Egypt, University of Alexandria, 1987.

10. Eadie PA, Williams R, Dickson WA. Thirty-five years of paediatric scalds: are lessons being learned? British joumal of plastic surgery, 1995, 48:103-5.

11. Green AR, Fairclough J, Sykes PJ. Epidemiology of burns in childhood. Bums, 1984, 10(5):368-71.

12. Etiba $A H$ et al. Burns and scalds among school-aged children in Alexandria. Bullotin of the High institute of Public Hoalth, 1984, 14(4):227-40.

13. Duggan D, Quine \$. Burn injuries and characterlstics of burn patlents in New 
South Wales, Australia. Burns, 1995, 21(2):83-9.

14. El-Sonbaty MA, El-Oteify M. Epidemlology of burns in Assiut province during the last two years. Assiut medical journal, 1990, 14:106-9.

15. de Kock $M$. The Cape Town burn profile. Bums, 1978, 5(2):210-1.

16. Jha SS. Burns mortality in Bombay. Bums, 1981, 8(2):118-22.

17. Adesunkanmi $K$, Oyelami $O A$, The pattern and outcome of burn injuries at Wesley Guild Hospital, llesha, Nigeria: a roviow of 166 cases. Journal of tropical medicine and hygiene, 1994, 97:108-12.

18. Forjuoh SN, Guyer B, Smith GS. Childhood Durns In Gnana: epldemlologlcal characteristics and home-based treatment. Burns, 1995, 21(1):24-8.

19. Jay KM. Burn epidemiology: a basis for burn prevention. Journal of trauma, 1977, 17(12):943-7.

20. Malla $C N$ ef al. Analytical study of burns in Kashmir. Bums, 1983, 9(3):180-3.

21. El-Muhtaseb H, Qaryouto S, Abu Raghob S. Burn injuries in Jordan: a study of 338 cases. Bums, 1983, 10(2):116-20.

22. Pegg SP et al. Epidemiology of burns attending a casualty department in Brisbane. Bums, 1983, 9(6):416-21.

23. Nagasaki T. Statistical analysis of burnt at Nagasaki Hospital in Hiroshima. Burns, 1978, 5(1):60-1.

24. Onuba $O$. Pattern of burn injury in Nigerian children. Tropical doctor, 1989, 18:106-8.

25. Pegg SP, Hinckley VM, Adiseshan N. Adult burns. A three-year survey with assessment of sulphamylon. Medical journal of Australia, 1972, 1:350.
26. Byrom RR et al. Epidemiology of flame burn injuries. Burns, 1984, 11(1):1-10.

27. Bowser BH et al. Statistical methods to predict morbidity and mortality: self-assessment techniques for burn units. Bums, 1983, 9:319-26.

28. Scott-Conner CEH et al. Quantitation of rate of wound closure and the prediction of death following major burns. Burns, 1988, 14:373-8.

29. Wong MK, Ngim ACK. Burns mortality and hospitalization time-a prospective statistical study of $\mathbf{3 5 2}$ patients in an Asian national burn centre. Bums, 1995, 21(1):39-46.

30. Benita-Ruiz I et al. An analysis of burn mortality: a report from a Spanish regional burn centre. Bums, 1991, 17:2014.

31. Shirani $K Z$, Pruitt BA, Mason AD. The influence of inhalation injury and pneumonia on burn mortality. Annals of surgery, 1986, 205:82-7.

32. Roi LD, Flora JD, Davis TM. Two new burn severity indices. Joumal of trauma, 1083, 23:1023-9.

33. Boutros SG. Health statistics. Ministry of Health. Personal communication, 1991.

34. Mock $\mathrm{CN}$ et al. Admissions for injury at a rural hospital in Ghana: implications for prevention in the developing world. American journal of public nealth, 1995, 85(7):927-31.

35. Scannell G, Waxman K, Tominaga GT. Respiratory distress in traumatized and burned children. Joumal of pediatric surgery, 1995, 30(4):612-4.

36. Langley J. Description and classification of childhood burns. Burns, 1984, 10(4):231-5. 